\title{
Diagnosis and Correction of Maladaptive Behavior in Older Preschoolers
}

\author{
Maria A. Gasilina ${ }^{1}$, Natalya V. Litvinenko ${ }^{1}$, Valentina A. Zebzeeva ${ }^{1, *}$, Altnay K. Mendygalieva ${ }^{2}$ \\ ${ }^{1}$ Department of Pedagogy for Preschool and Primary Education, Orenburg State Pedagogical University, Russian Federation \\ ${ }^{2}$ Department of Theory and Methods for Primary and Preschool Education, Orenburg State Pedagogical University, Russian \\ Federation
}

Received June 4, 2020; Revised July 18, 2020; Accepted August 10, 2020

\begin{abstract}
Cite This Paper in the following Citation Styles
(a): [1] Maria A. Gasilina, Natalya V. Litvinenko, Valentina A. Zebzeeva, Altnay K. Mendygalieva, "Diagnosis and Correction of Maladaptive Behavior in Older Preschoolers," Universal Journal of Educational Research, Vol. 8, No. 9, pp. 4313-4324, 2020. DOI: 10.13189/ujer.2020.080958.
\end{abstract}

(b): Maria A. Gasilina, Natalya V. Litvinenko, Valentina A. Zebzeeva, Altnay K. Mendygalieva (2020). Diagnosis and Correction of Maladaptive Behavior in Older Preschoolers. Universal Journal of Educational Research, 8(9), 4313-4324. DOI: 10.13189/ujer.2020.080958.

Copyright $\bigcirc 2020$ by authors, all rights reserved. Authors agree that this article remains permanently open access under the terms of the Creative Commons Attribution License 4.0 International License

\begin{abstract}
The older preschooler forms long-term psychological mechanisms for activity and behavior that ensure social adaptation. Maladaptive behavior indicates a lack of social skills and requires timely correction. The purpose of this study is to comprehensively diagnose and correct maladaptive behavior in children of senior preschool age. At the ascertaining stage of the experiment, a set of techniques was applied that made it possible to diagnose the factors, manifestations and consequences of maladaptive behavior in older preschoolers. Cluster analysis allowed us to describe the characteristics of children in selective aspects. Statistical analysis revealed that $42.55 \%$ of all the older preschool children displayed maladaptive behavior. The diagnosed criteria of maladaptive behavior included assessing factors of maladaptive behavior, identifying manifestation of maladaptive behavior and determining unfavorable group sociometric status. They formed the basis for the development and implementation of remedial programs during the formative stage of the experiment. The programs are aimed at shaping socially adequate behavior in older preschoolers, forming a positive attitude towards enrolling in and attending school, preventing negative emotional states and informing parents about the signs of maladaptive behavior in children. As a result, comprehensive diagnosis and timely correction of maladaptive behavior in older preschoolers ensure their readiness for school.
\end{abstract}

Keywords Senior Preschoolers, Diagnosis of Maladaptive Behavior, Remedial Programs

\section{Introduction}

The senior preschool age is when the foundations of a person's future personality are formed; it is when the formation of long-term psychological mechanisms for activity and behavior takes place. There is intensive development of social skills in this particular age period. Preschoolers assimilate social values and connect them with understandings of moral norms and societal rules for behavior. This assimilation indicates that a child of senior preschool age has adapted to social conditions, which in this case implies that the child has been accepted by society and has friends (Piqueras et al., 2019).

The family is the child's primary social environment. It must take care of, protect and support the child, as well as facilitate consistency between psychological mechanisms for activity and behavior and the child's daily experience (Moreno Manso et al., 2009). The family plays an important role in the preschooler's assimilation of social values when interacting with other people. Preschool educational institutions also form mechanisms of social adaptation in a child that are necessary for both children and adults (Vaskivska et al., 2018). 
With insufficient attention and support from family and teachers, a child will begin to show aggression, resistance and conflict (Côté et al., 2018), thereby experiencing behavioral problems. These problems can manifest externally and internally: they may include hyperactivity, rule breaking, aggression, nervousness, introversion, and depression (Hosokawa, Katsura, 2018). These problems indicate a lack of social skills that can prevent social adaptation in preschoolers at the proper level.

The problem of adapting preschool children to social conditions remains relevant and is associated with an increase in the number of children in preschool educational institutions with behavioral differences that are unable to obey general rules and behavior norms. The main reasons for such behavior include an individual inability to regulate emotions (Hernández et al., 2018), as well as prenatal maternal stress and a family's specific parenting style (Poulou, 2015). An overstated self-esteem may also indicate a preschooler's maladaptive behavior. At its core, maladjustment acts as a breakdown of a child's adaptive abilities, an imbalance in their psycho-physiological state, and a decrease in their potential, a state that makes it impossible for them to solve any problems. Instead, the child demonstrates maladaptive behavior, indicating a lack of social skills.

Maladaptive behavior in senior preschoolers is understood as the psychological state of an individual characterized by a lack of targeted activity towards interaction with the social environment. It manifests as inappropriate behavior in groups and a negative attitude towards peers and teachers. This condition arises alongside anxiety, aggression, and lowered self-esteem, which leads to an unfavorable sociometric status for a child and their unpreparedness for institutionalized education.

Both teachers and parents experience difficulties in raising these children. By considering the problem of maladjustment in children to be unimportant or exclusively attributing it to a teacher's abilities, parents are not ready for effective interaction with their children. Parent and teacher support in raising such children is important in order to ensure the timely correction of maladaptive behavior in preschoolers. Thus, adequate prevention of social maladjustment at the senior preschool age is required. This implies timely identification, prognosis of the probable degree of a child's maladjustment, and the qualified support of parents and teachers in raising these children.

Behavioral problems in preschoolers can lead to serious difficulties in the future. Accordingly, early diagnosis of maladaptive behavior can contribute to developmental corrections in preschool children (Munzer et al., 2018). A set of remedial programs aimed at eliminating the maladaptive behavior in preschoolers must be implemented. Such programs primarily involve strengthening interactions between parents and their child, introducing programs aimed at developing social skills in preschoolers, and reducing the level of behavioral problems.

The purpose of this study is to comprehensively diagnose and correct maladaptive behavior in children of senior preschool age. The diagnostic results allow us to propose a set of programs to correct this behavior, which is the essence of this study's hypothesis. Data on the indicators, severity, manifestations and consequences of maladaptive behavior in older preschoolers will help develop a set of remedial programs aimed at eliminating these problems that cover the most important areas of working with children.

\section{Literature Review and Analysis}

The preschool period is characterized by significant social development (Baiao et al., 2018), which is facilitated by the competent organization of modern preschool education, primarily aimed at developing a child's personality during their upbringing (Vaskivska et al., 2018). The child realizes that their inner and outer worlds are separate, but their desires and the behavioral manifestations of those desires can be a single whole. Therefore, the behavior of a preschooler can be described as "I wanted - I did." When the intellect is engaged, that behavior becomes more self-aware: "I wanted - I thought - I did" (Lavrent'eva, 2008).

The child, due to their short life experience, has to constantly adapt to new conditions at the preschool educational organization. Preschoolers have not yet reached the necessary level of emotional control or behavioral skills to demonstrate the social competence that ensures successful interaction in the social environment (Côté et al., 2018). In this regard, the role of teachers is important. They help preschool children adapt to their social environment, and if that adaptation is successful, a child can easily join a team without any difficulty communicating with adults or children. These circumstances describe a favorable sociometric status for a child.

Parents or legal representatives (hereinafter - the parents) play an essential role in raising a child and, accordingly, helping develop their social skills. The family environment must be stable and safe in order to foster co-habitation and the child's healthy development, and to meet their emotional and educational needs. Having a positive relationship with their parents will help a child understand the importance of emotions; otherwise they may have psychological problems in childhood and later on in adolescence. A child's relationship with their parents establishes a bond that grows stronger if the parents respond to the child's emotional signals. Developing this relationship will enable a child to use these skills in relationships with other people. Thus, a preschooler will be able to develop social skills and assimilate a system of social values (Moreno Manso et al., 2009). 
If this does not occur, a child will be unable to adapt to new social conditions, resulting in anxiety, aggressiveness and lowered self-esteem. A preschooler will express dissatisfaction with the social environment and disagreement with certain social rules and norms. Maladaptation occurs as a result of conflict with the social environment and is regarded as a child's inability to adapt to the social conditions in which they live. As a result, a preschooler will not assimilate social norms and values, which indicates a disruption in the process of socialization and, accordingly, a social maladaptation.

Maladaptive behavior occurs as a result of conflict which is beyond the child's power to control, resulting in misbehavior. Thus, maladaptive behavior is associated with an activity disruption in which a child is unable to change their actions and solve problems to establish interaction with the social environment. Meanwhile, psychological defense mechanisms are activated, which postpone the solution of this problem and lead to defensive behavior, environmental alienation, and lowered self-esteem.

Researchers from the United States note that maladaptive behavior is often associated with serious problems in adapting to the environment and health impairments, which results in a lack of social skills (Ostrov et al., 2018). As for other factors linked to maladaptive behavior, a child's lack of well-developed social skills and behaviors is influenced by their parents' level of stress and inadequate family support (Graziano et al., 2018: 1254).

Maladaptive behavior in older preschoolers is manifested by inappropriate group behavior, and the development of a negative attitude towards peers and teachers. Negative attitudes towards peers are characterized by an inability to empathize or consider the views and desires of other children, and also an ability to interact with peers in different activities. In turn, a negative attitude towards teachers manifests itself in mood disorders, including anxiety, fear, and apathy.

One of the most significant consequences of maladaptive behavior in children of preschool age is that it makes them unprepared for schooling. This lack of readiness can lead to difficulties in learning activities and a child's excessive impulsiveness, which manifests as weak self-control and insufficient awareness of actions, as well as the desire to avoid hypothetical failures and significant distrust of peers. This leads to a negative attitude towards enrolling in and staying in school. These children are not interested in future schooling and do not recognize the authority of the teacher.

The aspects of maladaptive behavior should be the basis of its comprehensive diagnosis, including the significant indicators, factors, manifestations, and consequences of maladaptive behavior in children of senior preschool age. Nevertheless, modern researchers pay a lot of attention to individual aspects, not all of them together. For example, researchers from Japan used questionnaires to study the characteristics of the family, family upbringing style, and the behavioral problems of children during the transition from a preschool educational institution to a general educational institution. They argue that authoritarian and permissive styles of family upbringing significantly influence the maladaptive behavior of preschoolers (Hosokawa, Katsura, 2018).

A researcher from Greece talks about the importance of diagnosing social skills and emotions in preschoolers (Poulou, 2015), while Spanish researchers offer a study of the characteristic features of emotional intelligence in a younger student (Piqueras et al., 2019). M. S. Poulou points out that there are difficulties in diagnosing adaptive behavior in preschoolers. She argues that these difficulties are associated with the different manifestations of this type of behavior, like rapid behavioral changes, the need to conform to social norms, and the expansion of social ties (Poulou, 2015).

The diagnosis should result in a change from maladaptive behavior to adaptive behavior in older preschoolers with the implementation of modern remedial programs. Australian researchers recommend one such program to improve parent-child interaction within the family, known as PCIT-CU (Parent-Child Interaction Therapy, callous-unemotional traits) (Kimonis et al., 2019). In this regard, Canadian researchers focus on the relationship between fathers and their children, which has a significant impact on the social adaptation of the latter (Bureau et al., 2017). Using other family upbringing styles also helps to correct the relationship between parents and children (Poulou, 2015). Researchers from Italy offer a program called "Coping Power," which aims to develop the social skills of preschoolers and reduce behavioral problems (Muratori et al., 2018).

But these remedial programs all have the same orientation. They mainly focus on correcting the relationship between the parents and the child or on the introduction of specialized programs by teachers in preschool educational organizations. There need to be comprehensive programs that address the main indicators and factors of maladaptive behavior in children of senior preschool age, its features, manifestations, and consequences. Since the comprehensive diagnosis and correction of maladaptive behavior in children of senior preschool age has not been studied sufficiently, the authors intend to comprehensively diagnose and correct maladaptive behavior in children of senior preschool age.

\section{Methods}

94 senior preschoolers participated in this study of the diagnosis and correction of maladaptive behavior. They all studied at preschool educational organizations in the city of Orenburg and the Orenburg Region (Russia). The research included two main stages: the ascertaining stage and the 
formative stage. At the ascertaining stage, maladaptive behaviors in children of senior preschool age were diagnosed in accordance with three criteria: assessing factors of maladaptive behavior, identifying manifestation of maladaptive behavior, and determining unfavorable group sociometric status.

\subsection{The Ascertaining Stage}

As per the first criterion, the factors of maladaptive behavior in children of senior preschool age were assessed: anxiety, aggressiveness, and low self-esteem. Anxiety refers to experiencing worry, helplessness, a lack of self-confidence, insecurity, and inability to independently make decisions. Aggression is stated as the use of physical force, expression of negative feelings in abnormal behavior and verbal abuse. Unawareness of physical and mental abilities, conduct, motives and purposes of one's behavior, attitudes towards other people and oneself characterize lowered self-esteem.

To identify anxiety levels, the methods of American psychologists R. Temmle, M. Dorki, and V. Amen were used, known as "Choose the Right Face" (Dermanova, 2002). This projective test involves studying anxiety levels in children in normal life situations. It is particularly helpful in identifying the inner attitude of a preschooler towards certain social situations. As part of this methodology, a series of pictures is presented in a strict sequence. After viewing each picture, the child needs to answer the question: "What kind of face do you think this child will have: happy or sad?" The answers (to questions and verbal statements) are recorded in a special log, as reflected in Table 1.

Table 1. "Choose the Right Face" methodology log

\begin{tabular}{|c|c|c|c|}
\hline \multirow[b]{2}{*}{ Picture } & \multirow{2}{*}{$\begin{array}{l}\text { Child's } \\
\text { Statement }\end{array}$} & \multicolumn{2}{|l|}{ Option } \\
\hline & & $\begin{array}{l}\text { Happy } \\
\text { Face }\end{array}$ & $\begin{array}{l}\text { Sad } \\
\text { Face }\end{array}$ \\
\hline $\begin{array}{l}\text { 1. Playing with younger } \\
\text { children }\end{array}$ & & & \\
\hline $\begin{array}{l}\text { 2. Child and mother with } \\
\text { baby }\end{array}$ & & & \\
\hline 3. Object of aggression & & & \\
\hline 4. Dressing & & & \\
\hline 5. Playing with older children & & & \\
\hline $\begin{array}{l}\text { 6. Laying down to sleep } \\
\text { alone }\end{array}$ & & & \\
\hline 7. Washing & & & \\
\hline 8. Scolding & & & \\
\hline 9. Ignoring & & & \\
\hline 10. Aggression & & & \\
\hline 11. Cleaning toys & & & \\
\hline 12. Isolation & & & \\
\hline 13. Child with parents & & & \\
\hline 14. Eating alone & & & \\
\hline
\end{tabular}

The level of anxiety of a preschooler is determined with the following formula: ratio of the number of "sad face" choices to the total number of pictures. A high level of anxiety is defined as a ratio over $50 \%$, a medium level is $20-50 \%$, and low is $0-20 \%$. Similar levels characterize subsequent techniques.

A determination of aggression levels was carried out based on L. and S. Bellak's methodology “The Children's Apperception Test" (Dermanova, 2002). It allows you to understand a child's attitude towards significant figures by associating them with animals to draw conclusions about the child's problems. After being presented with 10 pictures with animals in otherwise normal situations, the child needs to tell stories, describing what the animals are doing at that moment. Guiding questions from the researchers can help expand the child's story. All the preschooler's answers and actions regarding the locations of the animals, their characteristics, and the themes of the pictures are recorded for subsequent analysis.

V. G. Shchur's technique "The Ladder" (Dermanova, 2002) evaluates self-esteem in preschoolers. The method has a child put themselves on a certain step of a ladder (out of seven available steps). Then the child must explain why they did not put themselves on steps for children with certain characteristics: good or bad, kind or mean, clever or stupid, brave or cowardly. Then the child explains on which step their parents and teacher would put them. The researchers record the answers received and draw a conclusion about the child's self-esteem: excessively high, high, adequate, or low.

The second criterion involved identifying how maladaptive behavior in older preschoolers manifests itself: inappropriate group behavior and negative attitudes towards peers and caregivers. As regards inappropriate behavior in a group, children tend to reject, express a formal attitude towards, or manipulate norms and rules of group behavior. Negative attitudes towards peers are stated as nervousness, offendedness, irritancy, stubbornness, disagreements, conflicts; not initiating play with their peers and mutual aid in classes, not sympathizing with peers' failures and successes; preferring to play alone; inconsistencies between one's actions and peers' actions in play and in classes; inability to observe peers' wishes and mood and adapt to it. Exhibiting irritation, hot temper, frustration, alertness, worry and sensitivity to dispraise characterize negative attitudes of preschool children towards an educator.

A study of inadequate behavior was carried out using the diagnostic technique of R. Gilles "The Social Adequacy of Behavior" (Dermanova, 2002). It shows options for the different attitudes of older preschoolers towards the rules and behavioral norms in a group and in relationships with adults (parents and teachers): the adoption and observance of the rules, a formal attitude, manipulation, rejection of norms and rules of behavior. The child must give answers to 42 pictures shown to them, which depict children or children and adults; the child needs to determine their place 
among the characters or identify themselves among the people depicted. Then they must complete text exercises so researchers can determine their typical behavior.

A study of the attitudes of older preschoolers towards their peers was carried out using the observation method, which made it possible to identify different attitude levels. Such indicators as peer initiative, empathy, and interest in the actions of peers were analyzed.

Maladaptive behavior of older preschoolers was also expressed as a negative attitude towards the teacher. For this diagnosis, the projective drawing test by R. R. Kalinina "My Teacher" was used (Sharapova, 2017). The test aims to identify the health of a child's relationship with a teacher. Preschoolers are instructed to draw their teacher. When their work is analyzed, attention is paid to the style of the drawing and how it characterizes the child's attitude towards the teacher. The contents of the picture must also be considered to help determine the teacher's activities from the preschooler's point of view.

Diagnoses were made by studying the consequences of maladaptive behavior in older preschoolers. According to the third criterion, determinations were made on whether a student had unfavorable group sociometric status and was not ready for schooling, which was expressed by the student's underdeveloped self-esteem.

The sociometric status of preschool children in a peer group was studied according to the "Two Houses" method by T. D. Martsinkovskaya (Martsinkovskaya, 2000), which made it possible to identify different types of sociometric status in children of preschool age. To make this determination, two houses are presented on a sheet of paper: a large red house and a small black house. The subject needs to put 3-5 children from their group into one of the houses, while understanding that the large house belongs to them. Researchers fill in a matrix, placing in front of the last name of each child (in alphabetical order) a "+" (positive choice) or "-." (negative choice) as an indicator of whether they were placed in the large house or the small house, respectively. The sociometric status of a preschooler ("popular," "preferred," "ignored," "rejected") is determined by the average amount of positive scores they receive.

Student disposition development was studied using the conversation developed by T. A. Nezhnova "On Attitudes Towards School and Learning" (Nezhnova, 1988). It allows you to identify the different levels of this attitude's development in older preschoolers, the main components of which are a child's general attitude towards school and learning; orientation to new, relevant school curricula; orientation to new, relevant school forms for organizing activity and behavior; and recognition of the authority of the teacher. The conversation is individual and is built on a set of short stories, which are preceded by the question "Do you want to go to school?" Answers to questions about the short stories are rated as "school" or "preschool."

The empirical data obtained at this stage of the experiment on the factors, manifestations, and consequences of maladaptive behavior in older preschoolers were processed using cluster and statistical analysis. Cluster analysis allowed dividing the participants into homogeneous groups: "adapted" older preschoolers and older preschoolers with maladaptive behavior. The results obtained via the software STATISTICA Multivariate Exploratory Techniques (module Cluster Analysis) made the division possible. It was based on integrating the assessment results of all the participants on different diagnostic techniques. The identification of maladaptive behavior related to inappropriate group behavior, negative attitudes towards peers and caregivers, which arise from anxiety, aggressiveness and lowered self-esteem, and which result in unfavorable group sociometric status and unreadiness for schooling.

Processing the results obtained from diagnostic methods allows us to determine significant differences in these indicators by calculating the t-Student statistical parametric criterion and the Fisher angular transformation criterion of the selected groups of older preschoolers. The statistical data from pairwise comparisons between groups obtained in the study reflect the peculiarities of the behavioral sphere, attitudes towards peers and educators, the emotional well-being of the subjects, their position in the peer group (sociometric status in the group), and self-esteem. This reveals the statistical significance of differences in self-esteem between "adapted" older preschoolers and older preschoolers with maladaptive behavior.

Analyzing the data allows "adapted" older preschoolers and older preschoolers with maladaptive behavior to be identified. Preschoolers with adaptive behavior are included in the control group, and preschoolers with maladaptive behavior serve as the experimental group.

\subsection{The Formative Stage}

The formative stage aimed at eliminating maladaptive behavior in children in the experimental group at a preschool educational organization. The basis for organizing the educational environment was the idea of a having full-fledged preschool childhood and enriching (amplifying) child development (Khanova, Belinova, 2016). This idea implies extensive deployment and enrichment of the content of children's forms of play, communication and productive activities, as well as communication with peers and adults, taking into account the age and individual characteristics of older preschoolers. Implementing this idea in the educational process of a preschool educational organization contributes to the formation of favorable sociometric status in a group and readiness to study at school in children of senior preschool age with maladaptive behavior.

Considering the problems experienced by older preschoolers with maladaptive behavior, a set of remedial 
programs was developed aimed at eliminating these problems that cover the most important areas of working with children. These areas include the formation of socially adequate behavior in a group and in interaction with adults, cultivating a positive attitude towards enrollment and schooling, pedagogical prevention of negative emotional states, and informing parents about the characteristics of maladaptive behavior in children of preschool age. During the formative stage of the experiment, a set of programs was implemented, which are described in the "Research Results" section. Analysis of all the indicators is meant to prove the effectiveness or ineffectiveness of applying programs in practice during the formative stage of the experiment.

\section{Research Results}

\subsection{Assessing Factors of Maladaptive Behavior}

During the ascertaining stage of the experiment, a study was conducted on the factors of maladaptive behavior in children of preschool age. R. Temmle, M. Dorki, and V. Amen's method "Choose the Right Face" allowed the preschoolers' anxiety levels to be identified. The results of the study showed that $42.55 \%$ of children of senior preschool age showed high levels of anxiety, and average anxiety levels were found in $54.25 \%$ of senior preschool children. A low level of anxiety was recorded in $3.2 \%$ of the total number of children of senior preschool age who participated in the experiment.

Levels of aggression were determined using L. and S. Bellak's method "The Children's Apperception Test." 21.3\% of older preschoolers had a high level of aggression; they identified themselves in the pictures "Lion with a pipe" and "Tiger and monkey" with negative characters like the lion and tiger, respectively. An average level of aggression was found in $51.1 \%$ of older preschoolers; these children saw themselves as a wolf cub, bear cub, or mouse. $27.6 \%$ of older preschoolers displayed a low level of aggression; they only associated themselves with positive characters in the stories: a mouse (in the picture "Lion with a pipe"), a bear cub (in the picture "Bears dragging a rope"), animals (in the picture "Animals on the hill") and a monkey (in the picture "Tiger and monkey").

V. G. Shchur's technique "The Ladder" made it possible to determine self-esteem levels in children of senior preschool age. Understanding that self-esteem in children of senior preschool age is in a formative stage, we found that $8.5 \%$ of senior preschool children have inadequately high self-esteem, $21.3 \%$ have high self-esteem, $57.4 \%$ have adequate self-esteem and $12.8 \%$ of preschool age children have low self-esteem.

Statistically, all the groups are significantly different in terms of anxiety, aggression, and self-esteem. The most anxious and aggressive older preschoolers are preschoolers with maladaptive behavior $(\mathrm{p} \leq 0.001)$. Differences in self-esteem between adapted older preschoolers and older preschoolers with maladaptive behavior were found to be statistically significant. The highest number of older preschoolers with overstated self-esteem $(\mathrm{p} \leq 0.001)$ was found in older preschoolers with maladaptive behavior.

\subsection{Identifying Manifestation of Maladaptive Behavior}

A study of the maladaptive behavior of older preschoolers is presented below. The results of R. Gilles's method "The Social Adequacy of Behavior" showed options for different attitudes in older preschoolers towards behavioral rules and norms in a group, and in relationships with adults (parents and teachers). According to the study, $52.1 \%$ of children displayed an attitude of "acceptance and observance of the rules" regarding behavioral rules and norms. Inadequate group behavior was revealed in $47.9 \%$ of older preschoolers. They included preschoolers who demonstrated a formal attitude (18\%), manipulation (15\%), and rejection of behavioral norms and rules (14.9\%). $14.9 \%$ of senior preschoolers in the group were identified as rejecting behavioral norms and rules.

Analyzing pairwise comparisons of "adapted" older preschoolers with preschoolers with maladaptive behavior showed, for the indicator "inappropriate behavior in a group," that the former are statistically far superior to older preschoolers with maladaptive behavior $(p \leq 0.01)$ in adopting and observing rules. However, older preschoolers with maladaptive behavior are statistically far superior to "adapted" preschoolers in manipulating behavioral rules and norms in the group $(\mathrm{p} \leq 0.05)$.

A study of the characteristics of relations of senior preschoolers towards their peers yielded the following results. A high level of relations with peers was found in $19.15 \%$ of older preschoolers. An average level of relations between older preschoolers and their peers was observed in $64.89 \%$, while a low level was observed in $15.96 \%$.

Statistically, older preschoolers with maladaptive behavior are far more likely than "adapted" older preschoolers to have negative attitudes towards their peers $(p \leq 0.01)$, which manifests itself in their not initiating play with their peers $(p \leq 0.001)$, their preferring to play alone $(p \leq 0.05)$, and inconsistencies between their own actions and their peers' actions in play $(\mathrm{p} \leq 0.01)$.

A study of maladaptive behavior in older preschoolers showed that $43.6 \%$ displayed a high level of positivity towards the teacher, $35.1 \%$ of older preschoolers showed an average level of positivity towards the teacher, and $21.3 \%$ of older preschool children showed a low level of positivity towards the teacher.

For the indicator "attitude of preschool children towards an educator," comparing the results of the "adapted" group of senior preschool children with those of preschool children with maladaptive behavior showed that the 
"adapted" senior preschool children outperform senior preschool children with maladaptive behavior in having a positive attitude towards an educator. Older preschoolers with maladaptive behavior were more likely than "adapted" preschoolers to use gray $(\mathrm{p} \leq 0.05)$ and brown $(\mathrm{p} \leq 0.05)$ colors, which indicates that the children experienced stress.

\subsection{Determining Unfavorable Group Sociometric Status}

Different types of sociometric status in children of senior preschool age were also revealed. The sociometric status "popular" was found in $21.3 \%$ of older preschoolers. These preschoolers received the most positive choices (more than four). "Preferred" status was found in 59.5\% of older preschoolers; they received from one to four positive choices. The sociometric status "ignored" was revealed for $16 \%$ of older preschoolers; these are children who received neither positive nor negative choices. "Rejected" sociometric status was found for $3.2 \%$ of children of senior preschool age; they received only negative choices.

For the indicator "sociometric status of a child in a group," "adapted" children outnumbered children with maladaptive behavior in the "popular" group $(p \leq 0.001)$. Older preschoolers with maladaptive behavior outnumber "adapted" children in the "ignored" group $(\mathrm{p} \leq 0.001)$.

The results of the conversation "On Attitudes Towards School and Learning" showed that, in the ascertaining stage, $6.4 \%$ of children of senior preschool age displayed a high level of student disposition development, $70.2 \%$ of preschoolers showed an average level of student disposition development, and $23.4 \%$ of older preschoolers showed a low level of student disposition development.

The differences in the student disposition development of "adapted" older preschoolers and older preschoolers with maladaptive behavior were statistically significant as well $(p \leq 0.001)$. The majority of "adapted" senior preschoolers displayed a high level of student disposition development.

Empirical data obtained in the ascertaining stage of the experiment show that $57.45 \%$ of the older preschool children are "adapted," while $42.55 \%$ have maladaptive behavior. Calculating the t-Student statistical parametric criterion and the Fisher angular transformation criterion facilitated the correct designation of older preschool children as "adapted" or displaying maladaptive behavior according to the selected indicators, and described their characteristic features.

\subsection{Proposing Remedial Programs}

During the formative stage of the experiment, a set of remedial programs was implemented under the names: "Forming Socially Adequate Behavior in Senior Preschoolers in a Group or in Interaction with Adults," "Forming a Positive Attitude Among Older Preschool
Children Towards Enrollment and Schooling," "Pedagogical Prevention of Negative Emotional States in Children of Preschool Age," and "Informing Parents about the Characteristics of Maladaptive Behavior in Children of Senior Preschool Age." They meant to eliminate inappropriate group behavior and overcome negative attitudes towards peers and caregivers.

The program "Forming Socially Adequate Behavior in Senior Preschoolers in a Group or in Interaction with Adults" is aimed at educating children about having a positive attitude towards social rules of behavior. The primary methods employed by the educator in working with children were the creation of educational situations, word games, conversations based on reading stories and poems, explanation, clarification, using examples, and using pictures about "Rules of behavior in kindergarten."

The first section of this program, "Rules of behavior in a group," aimed to consolidate senior preschoolers' knowledge about the rules and norms of behavior at the table, in the classroom, in the group's play area, in the changing room, and in kindergarten. The second section, "Rules of behavior at school," was aimed at familiarizing preschoolers with the rules and norms of behavior in the classroom, at recess, in the school library, in the school cafeteria and during lessons.

The program "Forming a Positive Attitude Among Older Preschool Children Towards Enrollment and Schooling," aims to form positive motivations for learning in children with maladaptive behavior and a positive emotional attitude towards school. This program orients children to upcoming educational activities at school and gives them a meaningful idea about preparing for school. It also contributes to forming constructive skills for communicating with peers.

This program includes the sections: "School is Soon" and "Me and Society." The first section of the program "School is Soon" is aimed at developing knowledge about the teacher's profession among senior preschoolers. It talks about the main differences between school and kindergarten and helps familiarize older preschoolers with school clothes and school supplies. The second section of the program "Me and Society" is aimed at forming constructive skills for interacting with peers and adults, which aids in the development of mutual understanding and empathy for adults and peers. This section allows children to overcome feeling alienated from their peers and gives them a healthier perception of this relationship.

The program "Pedagogical Prevention of Negative Emotional States in Children of Preschool Age" is aimed at eliminating children's fears, internal stress, stiffness, and anxiety. It helps ensure a stable mood so they can develop self-esteem.

This program contains such sections as "In the world of emotions" and "My self-esteem." The first section of the program is aimed at reducing anxiety, aggression, and emotional stress and developing the ability to overcome 
negative experiences. The second section involves the formation of adequate self-esteem and aims to increase low self-esteem in older preschoolers. A distinctive feature of this program is its focus on the development of mental processes through various means. For example, developmental classes use various drawing techniques: "Monotype," "Drawing with yarn," "Plasticine modeling," "Hatching." Other tools are also used, such as cards with images depicting various emotional states in children and adults and children's fiction. It should also be noted that "LEGO" materials were used in children's joint developmental activities, which are building toys consisting of parts for assembling and modeling various objects.

During the program "Informing Parents about the Characteristics of Maladaptive Behavior in Children of Senior Preschool Age," parents are introduced to the characteristics of maladaptive behavior in older preschool children. In this regard, they learn about the main causes of this phenomenon, as well as methods, forms, and means to prevent maladaptive behavior in children.

This program was mainly implemented using seminars and workshops on the following modules: "The maladaptation of preschool children to the educational environment of a preschool educational organization," "Maladaptive behavior in older preschool children in the educational environment of a preschool organization," and "Pedagogical conditions for the prevention of maladaptive behavior in older preschool children." This remedial program not only includes seminars and workshops with parents, but also discussions. Their main content is aimed at forming ideas about the maladaptive behavior of older preschoolers, and familiarizing parents with both the main causes of this phenomenon, as well as ways to prevent maladaptive behavior in older preschoolers.

\section{Interpretation of Research Results}

\subsection{Diagnosing Maladaptive Behaviors}

The division of senior preschoolers into two groups is associated with the participants exhibiting anxiety. A high level of anxiety was characteristic of those with maladaptive behavior, while "adapted" senior preschoolers did not have such. Determining anxiety levels in senior preschoolers allowed for a qualitative analysis to determine the nature of a child's emotional experience in a social situation. That analysis showed that anxiety and fear are associated with personal experiences, including negative emotional experiences in situations modeling a "child-child" relationship. In this regard, a high level of anxiety was noted among preschoolers who mainly chose the pictures "Playing with younger children," "Playing with older children," "Ignoring," "Aggression," and "Isolation." The results of "child-adult" interaction showed both high and medium anxiety levels in preschoolers with varying degrees of strained relations in the family. With an average level of anxiety, a sad face was noted when "Scolding" and "Ignoring" were chosen. Meanwhile, the choices "Child and mother with baby" and "Child with parents" are more typical for preschoolers with a high level of anxiety. In situations that simulate daily activities, preschoolers with an average level of anxiety are more likely to choose "Dressing," "Laying down to sleep alone," "Ignoring," and "Eating alone."

Aggression levels indicate the basic needs and motives of older preschoolers. Associating with negative characters, which themselves display aggressive behavior, or expressing hostility towards them is inherent in children with a high level of aggression. This is explained by such statements from children as "the tiger is strong and clever" and "the lion is the king of beasts, many animals are afraid of him." When identifying with animals, older preschoolers can describe both their negative and positive characteristics. In this case, children had an average level of aggression. Their explanations were as follows: "The wolf cub is brave and mischievous; he has many friends who like to play with him and ride down the hill"; "The bear is cheerful and strong"; "The mouse is clever and sly."

Inadequate self-esteem in preschoolers can be either high or low. An incorrect self-assessment is usually associated with the child putting themselves on a high step on the ladder, and explaining their choice like an adult-this is how an inadequately high level of self-esteem is identified. When self-esteem is overstated, the child partially understands their shortcomings, as adults explain them, but they consider them insignificant. The child not justifying their choice ("I do not know") or refusing to complete the task indicates low self-esteem, as well as a high level of anxiety.

Upon analyzing the results of "The Social Adequacy of Behavior" methodology, it was found that preschool children with a formal attitude towards behavioral rules and norms know and understand the rules, accept them, and try to follow them. When completing assignments, these preschoolers chose answers that included positive actions in problematic situations and explained their choices. With inadequate group behavior, children know the rules and norms of behavior, but do not delve into how they work. Older preschoolers with a formal attitude towards the rules and norms of behavior chose response options that included both positive and negative actions in the problematic situations presented. For example, in completing the fourth task ("Your classmate deliberately pushed you and knocked you down. What are you going to do?"), from the available answers ("you will cry"; "you will complain to the teacher"; "you will hit your classmate"; "you will talk to them"; "you will not say anything"), the children chose either the first or the last answer. To the question "How should one act in this situation?" the preschool children answered correctly that "in this 
situation, you should talk to your classmate." Preschoolers who manipulated the norms and rules of behavior in the group chose answers that included both positive and negative actions in the conflict situations presented. For these children, the choice of action to solve a problem situation depended on such goals as drawing attention to oneself, being convinced of one's own importance, or getting praise from the teacher. Older preschoolers who rejected the rules and norms of behavior knew the norms and rules of behavior in the group, but ignored them; they chose response options that caused a negative effect in the problem situations.

After analyzing the different levels of children's attitudes towards their peers, the authors have made a conclusion. A high level of peer relations indicates that these children gladly responded to their peers' initiative, actively picked up their ideas, showed empathy, empathized with their failures, showed a keen interest in peer actions (made comments), and did not shout at their peers or insult them. Older preschoolers with an average level of peer relations showed initiative, but were not persistent; they rarely responded to peer initiative and showed little interest in their actions (for example, while watching their peers play, they were quickly distracted). They rarely empathized with their peers' failures. When children asked for help, for example, to complete a math problem, if they did help, it was with great reluctance and only after they finished the problem themselves. These children were irritable towards their peers and sometimes ridiculed them (for example, when making clay models, older preschoolers told their peers that they would fail). Preschoolers with low peer relations did not take initiative in joint activities with peers and preferred to play alone. They also did not respond to other children's initiative, did not pay attention to the actions of their peers, and did not try to assist them in the classroom. They did not empathize with failures, and were not happy with their peers' success. They constantly shouted at or insulted the other children.

Analyzing data from the "My Teacher" projective drawing test showed that preschoolers with a highly positive attitude towards their teacher drew them in the center of the picture, at full-length, drew all the parts of the body well, and used bright colors. Preschoolers with an average positive attitude towards their teacher depicted them close-up, covering their clothes with patterns. Despite having a positive attitude towards their teacher, these preschoolers experience anxiety (manifested by the picture's shading) and a need for communication (this is evidenced by the chosen color spectrum, which includes purple and blue). Negative attitudes were manifested by the teacher's portrayal at the edge of the sheet of paper, drawing them small with some body parts missing (legs and hands), drawing them with jewelry, clothing patterns, and with symbols of aggression (highlighted, shaded red mouth; frayed hair) or using pale colors (gray and black).

A study of group sociometric status and student disposition development in senior preschoolers found the following. Older preschoolers with "popular" status tend to have leadership qualities, are demonstrative and sociable, and can resolve difficult situations that arise in the group. Preschoolers with "preferred" sociometric status tend to have a rather high level of popularity among other children, but they do not occupy leadership positions. Still, they feel comfortable in the peer group. "Ignored" preschoolers are passive, unsociable, feel comfortable alone and do not seek to expand their social circle. They are unemotional and unconfident. Older preschoolers with "rejected" status are characterized by bad moods, hostility towards other children, secrecy, a desire for protection, and a lack of initiative when communicating with other children.

Analyzing the development of a student disposition in senior preschoolers shows that children with a high level of development have a positive attitude towards enrolling in school. They preferred a school where the rules of discipline are observed, where there are collective classes and where grades are an important element of academic work. Older preschoolers with a high level of student disposition development have a meaningful understanding about preparing for school. They understand that you need to "count and write," "read books about animals and plants," and "tell stories," and that "lessons are taught by a teacher, not by a mother." With an average level of student disposition development, preschoolers are aware of the formal side of school life associated with the need to comply with school norms and rules. But they do not always show interest in the educational component of school life, especially in school assignments. A low level of student disposition development is found in those preschoolers who do not want to attend school and do not fully understand the role of the teacher. Such children do not understand the social significance of learning and, accordingly, do not show interest in its components.

Thus, by performing cluster and statistical analysis on the data obtained, "adapted" senior preschoolers and senior preschoolers with maladaptive behavior could be identified, and their individual characteristics explained.

\subsection{Eliminating Maladaptive Behaviors}

The formative stage was based on humanistic and personality-development principles of interaction between adults and children, supporting initiative, activity, and a child's independent activity in various forms (play, communicative, productive, literary comprehension). These principles make up the theoretical basis of the model for preventing maladaptive behavior in children in preschool educational organizations and support the use of value-based, student-centered, and activity-based approaches. Teacher activities focused on supporting individuality, children's interests, initiative, activity level, and independence in various forms (play, communicative, productive, literary comprehension). 
In the remedial program "Forming Socially Adequate Behavior in Senior Preschoolers in a Group or in Interaction with Adults," emphasis was placed on the joint analysis of upbringing situations. It provided children with necessary knowledge about behavioral rules in situations they encounter, and how to resolve them. Another important aspect of this program was consolidating knowledge about behavioral rules and norms in public places, in a kindergarten group, and at school.

In the remedial program "Forming a Positive Attitude Among Older Preschool Children Towards Enrollment and Schooling," various methods and forms of work were applied. Conversations about school contributed to the formation of a positive attitude towards enrollment and schooling. Examining thematic pictures and reading stories and poems about school contributed to greater understanding in older preschoolers about school uniforms and accessories. Role-playing games gave older preschoolers knowledge about how school works and about schooling itself. Skills for constructive interaction with peers were also developed.

The remedial program "Pedagogical Prevention of Negative Emotional States in Children of Preschool Age" focuses on the development of mental processes, namely: attention, memory, cognition, imagination, and speech. The use of various drawing techniques, cards with images of various emotional states, children's fiction, and LEGO materials contributed to the development of friendliness, understanding of others, mutual tolerance, flexibility, and ability to work in a group, and it also removed emotional stress in senior preschoolers.

The remedial program "Informing Parents about the Characteristics of Maladaptive Behavior in Children of Senior Preschool Age" was mainly implemented as seminars, workshops, and discussion. This instruction provided parents with necessary information about the indicators, factors, manifestations and consequences of maladaptive behavior in older preschoolers. The program contributed to the formation of ideas about the manifestations of maladaptive behavior, diagnostic methods related to identifying maladaptive behavior in older preschoolers, and about methods, forms, and tools aimed at preventing maladaptive behavior.

The effectiveness of applying the following remedial programs in practice has been demonstrated: "Forming Socially Adequate Behavior in Senior Preschoolers in a Group or in Interaction with Adults"; "Forming a Positive Attitude Among Older Preschool Children Towards Enrollment and Schooling"; "Pedagogical Prevention of Negative Emotional States in Children of Preschool Age"; and "Informing Parents about the Characteristics of Maladaptive Behavior in Children of Senior Preschool Age." The programs are diverse, covering not only the activities of teachers, but parents as well, in the prevention of social maladjustment. The efficacy of these programs was facilitated by a comprehensive diagnosis of children's maladaptive behavior, which confirms the hypothesis of this study. This represents the practical significance of this study for organizing the international practice of preschool education.

It is important to implement remedial programs after a comprehensive diagnosis that indicates the existing difficulties in children of older school age. Preschoolers have behavioral difficulties that are more susceptible to negative consequences (Muratori et al., 2018). Destructive internal contradictions, which cannot be resolved in a timely manner, have a much heavier impact on the emerging personality. Children who exhibit maladaptive behavior tend to demonstrate aggressive antisocial behavior that is difficult for parents to remedy (Kimonis et al., 2019).

Teachers need to account for the features of a preschooler's modern socio-cultural space in order to "ensure cohesion between public preschool education and family upbringing" while interacting with the preschooler's parents (Khanova, Belinova, 2016:86). This interaction will help prevent preschoolers' antisocial behavior, which may arise as a result of late corrective work.

\section{Conclusions}

The assimilation of a system of social values indicates that a child of senior preschool age has adapted to social conditions. But external and internal problems can hinder the full development of social skills in older preschoolers. This manifests maladaptive behavior in children of senior preschool age. Such children cannot purposefully interact with their social environment, tend to behave inadequately in a group and have a negative attitude towards their peers and teachers.

Adequate prevention of social maladjustment at the senior preschool age is based on the early comprehensive diagnosis of maladaptive behavior. This contributes to correcting the development of preschool children through the implementation of a set of remedial programs. Since comprehensive diagnosis and appropriate correction of maladaptive behavior in children of senior preschool age have not been studied sufficiently, this scientific article also presents the results of other relevant research in this area.

In the ascertaining stage, a comprehensive diagnosis was made of maladaptive behavior in children of senior preschool age. For this purpose, the following factors of maladaptive behavior in older preschoolers were assessed: anxiety, aggressiveness, and inadequate self-esteem. Manifestations of their maladaptive behavior were also determined: inadequate behavior in a group, as well as a negative attitude towards peers and caregivers. Consequences of maladaptive behavior in older preschoolers were also studied in this stage, namely: 
unfavorable sociometric status in a group and unreadiness for school. The cluster and statistical analysis of the data obtained allowed "adapted" children to be identified, and included in the control group, and children with maladaptive behavior to be identified and placed in the experimental group.

In the formative stage, a set of remedial programs was implemented, aimed at eliminating maladaptive behavior in children in the conditions of a preschool educational organization. In this stage, diagnosable factors, manifestations and consequences of maladaptive behavior in older preschoolers were taken into account. Analyzing these aspects proved the effectiveness of applying remedial programs in practice; indeed, this is how the research hypothesis was proved.

The results of this study will be useful to all teachers at preschool educational organizations who have difficulties in developing the social skills of older preschoolers. Using a set of diagnostic methods will allow teachers to focus on children who have difficulties in social adaptation in a timely manner, so they can begin remedial work at the right time.

As a result, the diagnosis and timely correction of maladaptive behavior in older preschoolers ensure their readiness for school. The authors intend to continue this study by examining changes in anxiety, aggressiveness and self-esteem in older preschoolers with maladaptive behavior as a qualitative research design. Also, it is planned to measure the effectiveness of the implemented remedial programs using quantitative and statistical research methods. In this regard, the authors intend to make recommendations about teaching children in schools who were previously diagnosed with maladaptive behavior that was subsequently corrected in remedial programs. Recommendations are also needed for teaching children in schools for whom maladaptive behavior has not been completely eliminated in preschool remedial programs.

\section{REFERENCES}

[1] Adler, A. (2017), Individual'naya psihologiya i razvitie rebenka (Individual psychology and child development), Moscow, Institut obshchegumanitarnyh issledovanij (Institute for Humanitarian Studies).

[2] Baiao, R., Baptista, J., Carneiro, A., Pinto, R., Toscano, C., Fearon, P., Mesquita, A. R. (2018), Assessing preschoolers interactive behaviour: A validation study of the "Coding System for Mother-Child Interaction", Child: Care, Health and Development, vol. 44, n. 4, 644-650.

[3] Biktina, N. N. (2016), Shkol'naya dezadaptaciya kak sledstvie psihologicheskogo neblagopoluchiya obrazovatel'noj sredy (School disadaptation as a result of the psychological distress of the educational environment), Problemy sovremennogo pedagogicheskogo obrazovaniya (Problems of modern pedagogical education), vol. 53, n. 3,
$370-375$

[4] Bureau, J.-F., Martin, J., Yurkowski, K., Schmiedel, S., Quan, J., Moss, E., Pallanca, D. (2017), Correlates of childfather and child-mother attachment in the preschool years, Attachment and Human Development, vol. 19, n. 2, 130150.

[5] Côté, S. M., Larose, M.-P., Geoffroy, M. C., Laurin, J., Vitaro, F., Tremblay, R. E., Ouellet-Morin, I. (2018), Testing the impact of a social skill training versus waiting list control group for the reduction of disruptive behaviors and stress among preschool children in child care: The study protocol for a cluster randomized trial, BMC Psychology, vol. 5, n. 1

[6] Dermanova, I. B. (2002), Diagnostika emocional'nonravstvennogo razvitiya (Diagnostics of emotional and moral development.). Saint-Petersburg, Rech'.

[7] Graziano, P. A., Ros, R., Hart, K. C., Slavec, J. (2018), Summer treatment program for preschoolers with externalizing behavior problems: A preliminary examination of parenting outcomes, Journal of Abnormal Child Psychology, vol. 46, n. 6, 1253-1265.

[8] Hernández, M. M., Eisenberg, N., Valiente, C., Spinrad, T. L., Berger, R. H., Johns, S. K., Thompson, M. S. (2018), Emotions in school and symptoms of psychological maladjustment from kindergarten to first grade, Journal of Experimental Child Psychology, n. 176, 101-112.

[9] Hosokawa, R., Katsura, T. (2018), Role of parenting style in children's behavioral problems through the transition from preschool to elementary school according to gender in Japan, International Journal of Environmental Research and Public Health, vol. 16, n. 21, 1-17.

[10] Khanova, T. G., Belinova, N. V. (2016), Psihologopedagogicheskie osnovy sovremennogo doshkol'nogo obrazovaniya (Psychological and pedagogical foundations of modern preschool education), Obshchestvo: sociologiya, psihologiya, pedagogika (Society: sociology, psychology, pedagogy), n. 5, 84-86.

[11] Kimonis, E. R., Fleming, G., Briggs, N., Brouwer-French, L., Frick, P. J., Hawes, D. J., Dadds, M. (2019), Parent-child interaction therapy adapted for preschoolers with callousunemotional traits: An open trial pilot study, Journal of Clinical Child, Adolescent Psychology, vol. 48, n. 1, 347361.

[12] Lavrent'eva, M. V. (2008), Obshchaya harakteristika razvitiya detej starshego doshkol'nogo vozrasta (General description of the development of older preschool children), Slovo: pravoslavnyj obrazovatel'nyj portal (Word: Orthodox educational portal). Retrieved from: https://www.portal-slo vo.ru/pre_school_education/36728.php

[13] Marcinkovskaya, T. D. (2000), Detskaya prakticheskaya psihologiya: uchebnik. (Children's practical psychology: a textbook.), Moscow, Gardariki.

[14] Moreno Manso, J. M., Garcia-Baamonde Sánchez y Macarena Blázquez Alonso, M. E. (2009), Social adaptation and communicative competence in children in care. Children and Youth Services Review, vol. 31, n. 6, 642-648.

[15] Munzer, T. G., Miller, A. L., Brophy-Herb, H. E., Peterson, K. E., Horodynski, M. A., Contreras, D., Lumeng, J. C. 
(2018), Characteristics associated with parent-teacher concordance on child behavior problem ratings in lowincome preschoolers, Academic Pediatrics, vol. 18, n. 4, $452-459$.

[16] Muratori, P., Giuli, C., Bertacchi, I., Orsolini, L., Ruglioni, L., Lochman, J. E. (2016), Coping power for preschool aged children: A pilot randomized control trial study, Early Intervention in Psychiatry, vol. 11, n. 6, 532-538.

[17] Nezhnova, T. A. (1988), Dinamika «vnutrennej pozicii» pri perekhode ot doshkol'nogo $k$ mladshemu shkol'nomu vozrastu (Dynamics of the "internal position" in the transition from preschool to primary school age), Vestnik Moskovskogo universiteta (Moscow University Bulletin), ser. 14 , n. $1,50-61$.

[18] Ostrov, J. M., Kamper-DeMarco, K. E., Blakely-McClure, S. J., Perry, K. J., Mutignani, L. (2018), Prospective associations between aggression/bullying and adjustment in preschool: Is general aggression different from bullying behavior? Journal of Child and Family Studies, vol. 28, n. 9, 2572-2585.

[19] Piqueras, J. A., Mateu-Martínez, O., Cejudo, J., PérezGonzález, J.-C. (2019), Pathways into psychosocial adjustment in children: Modeling the effects of Trait Emotional Intelligence, social-emotional problems, and gender, Frontiers in Psychology, vol. 10, 1-11.

[20] Poulou, M. S. (2015), Emotional and behavioural difficulties in preschool, Journal of Child and Family Studies, vol. 24,
$225-236$

[21] Shapoval, I. A. (2016), Psihologiya disgarmonicheskogo dizantogeneza. Psihogennye rasstrojstva $i$ razvitie (Psychology of disharmonious disantogenesis. Psychogenic disorders and development), 2 ed, Moscow, Flinta [1 ed. 2009, Orenburg, Detstvo: Izdatel'stvo Orenburgskogo gosudarstvennogo pedagogicheskogo universiteta].

[22] Sharapova, N. N. (2017), Formirovanie navykov polozhitel'nogo vzaimodejstviya doshkol'nika so vzroslymi v processe realizacii obrazovatel'noj oblasti "Social'nokommunikativnoe razvitie" (Formation of skills of positive interaction of a preschooler with adults in the process of implementation of the educational field "Social and communicative development"). Retrieved from: https://infourok.ru/formirovanie-navikov-polozhitelnogo-vz aimodeystviya-doshkolnika-s-vzroslimi-v-processe-realizac ii-obrazovatelnoy-oblasti-socialn-2091608.html

[23] Vaskivska, H. O., Palamar, S. P., Kondratiuk, S. G., Zhelanova, V. V. (2018), Psychodidactic determinants of the development of children of preschool age, Wiadomosci lekarskie, vol. 71, n. 6, 1207-1214.

[24] Yoder, M. L., Williford, A. P. (2019), Teacher perception of preschool disruptive behavior: Prevalence and contributing factors, Early Education and Development, 1-19.

[25] Ziv, Y. (2012), Exposure to violence, social information processing, and problem behavior in preschool children, Aggressive Behavior, vol. 38, n. 6, 429-441. 